\title{
Morphine-induced taste aversions: A consideration of parameters
}

\author{
ANTHONY L. RILEY \\ The American University, Washington, D. C. 20016 \\ and \\ W. J. JACOBS and VINCENT M. LoLORDO \\ Dalhousie University, Halifax, Nova Scotia B3H 4JI, Canada
}

\begin{abstract}
Following consumption of saccharin, groups of rats were injected with various doses of morphine sulfate. Although no aversion was found after one conditioning trial, repeated saccharin-morphine pairings resulted in decreases in consumption of the saccharin solution. On the average, however, the groups of rats showed only a moderate aversion, independent of the dose of morphine. Although there was little variability in consumption among rats that received the smallest dose of morphine, there was considerable individual variability among subjects receiving the larger doses. The differences between morphine-based conditioned taste aversions and aversions based on emetic USs were discussed.
\end{abstract}

Recently, a substantial amount of research on conditioned taste aversions has focused upon the specific "toxin" paired with consumption during conditioning (Berger, 1972; Gamzu, 1977; Ionescu \& Burešova, 1977; Martin \& Storlien, 1976; Nachman \& Hartley, 1975). Although initially demonstrated in rats poisoned by X-irradiation (Garcia, Kimeldorf, \& Koelling, 1955), conditioned taste aversions have now been induced by a wide range of pharmacological agents from a large number of drug classes (Riley \& Clarke, 1977). While emetics such as $\mathrm{LiCl}$, cytoxan, and emetine are used most frequently to establish aversions, drugs from such diverse classes as stimulants (amphetamine, nicotine), minor tranqulizers (chlordiazepoxide, meprobamate), anesthetics (ether, phenobarbital), and narcotics (morphine) are effective in inducing food aversions.

One drug which has generated considerable interest is the narcotic, morphine. This interest arose primarily from the paradoxical findings that not only does morphine function as a punisher in conditioning aversions, but that it is also readily self-administered, suggesting that morphine also functions as a rein-

This research was supported by the National Research Council of Canada, Grant A-9585 to V.M.L. A.L.R. was supported by an Izaak Walton Killam postdoctoral fellowship during the conduct of this research. W.J.J. was supported by a grant from Research on Drug Abuse of Canada. The authors would like to thank Linda L. Baril, Constance M. Clarke, Janet Lord, and Barry G. Watson for their assistance throughout this research. Requests for reprints should be sent to Anthony L. Riley, Department of Psychology, The American University, Washington, D.C. 20016. forcer (Cappell \& LeBlanc, in press, Goudie \& Thornton, 1975; White, Sklar, \& Amit, 1977; Wise, Yokel, \& deWitt, 1976). Procedural differences between the two experimental designs, such as route of administration, chronic vs. acute drug action, and dosimetry, may contribute to the dual effect of morphine. Nonetheless, when these major variables are equated, both conditioned aversions and selfadministration occur (White et al., 1977; Wise et al., 1976).

Although a number of researchers have found morphine to be an effective US in conditioning aversions (Amit, Levitan, Brown, \& Rogan, in press; Cappell \& LeBlanc, 1977; Cappell, LeBlanc, \& Endrenyi, 1973; Cappell, LeBlanc, \& Herling, 1975; Coussens, 1974; Farber, Gorman, \& Reid, 1976; Goudie, Thornton, \& Wheeler, 1976; Jacquet, 1973; LeBlanc \& Cappell, 1974, 1975; Parker, Failor, \& Weidman, 1973; Sklar \& Amit, in press; White et al., 1977), morphine-induced aversions often take more than one trial to develop (Berger, 1972; Cappell \& LeBlanc, 1977; Coussens, Crowder, \& Davis, 1973; Farber et al., 1976; LeBlanc \& Cappell, 1975) and are typically incomplete even after repeated conditioning trials (Cappell et al., 1973; Farber et al., 1976; Goudie et al., 1976; Jacquet, 1973; Parker et al., 1973). The acquisition and strength of morphineinduced aversions are in marked contrast to aversions established by emetics. LiCl-induced aversions, for example, typically take only one trial to develop (Nachman \& Ashe, 1973; Nachman \& Hartley, 1975) and are complete, i.e., total suppression of consumption, with repeated conditioning trials (Fenwick, 
Mikulka, \& Klein, 1975; Riley, Jacobs, \& LoLordo, 1976).

It is possible that the difference in the acquisition and strength of aversions established by morphine and emetics are a result of different physiological mechanisms underlying the conditioned aversions (Amit, Levitan, Brown, \& Rogan, in press; Cappell \& LeBlanc, in press; Elkins, 1974; Sklar \& Amit, in press). Amit et al. (in press), for example, have suggested that aversions induced by morphine and other drugs of abuse are based on the drugs' central action, whereas emetic drugs like $\mathrm{LiCl}$ act primarily at a peripheral level, e.g., by producing local tissue damage.

It is also possible, however, that these differences in results reflect parametric differences among individual studies examining morphine and emetic-induced aversions. To examine this possibility, in the following experiment, morphine was paired with a novel saccharin solution under parametric conditions which result in food aversions when $\mathrm{LiCl}$ is used as the US (Riley et al., 1976). Several parameters which affect the strength of $\mathrm{LiCl}$-induced aversions, e.g., repeated conditioning trials (Fenwick et al., 1975; Garcia \& Koelling, 1966) and higher doses (Nachman \& Ashe, 1973; Rolls \& Rolls, 1973) were also examined. These parametric manipulations allow us to assess the similarity of the effects of morphine and emetics in conditioning taste aversions.

\section{METHOD}

\section{Subjects}

Subjects were 36 experimentally naive, female rats of Long-Evans descent, approximately 90-120 days of age. They were maintained on ad-lib access to food but were water-deprived throughout the experiment. All the rats were maintained on a 12 -h light/12-h dark cycle for the duration of the experiment.

\begin{abstract}
Apparatus
The rats were housed in individual wire-mesh cages. In the front of each cage were two openings into which graduated Nalgene tubes were placed for presentations of water and/or sodium
\end{abstract} saccharin (1 g/liter).

\section{Procedure}

Phase 1. Rats were given 20-min access to water once a day for 12 consecutive days, at which point all rats approached and drank from the tube within $2 \mathrm{sec}$ of its presentation. Then different treatments were administered to five groups of randomly selected rats. On Day 13, Group $10(n=6)$ was given 20-min access to a novel saccharin solution followed immediately by an intraperitoneal (IP) injection of $10 \mathrm{mg} / \mathrm{kg}$ morphine sulfate. Similarly, Groups 20,50 , and 80 ( $n=8$ for each group) were given 20-min access to saccharin, followed immediately by an IP injection of 20,50 , and $80 \mathrm{mg} / \mathrm{kg}$ morphine sulfate, respectively. Group $C(n=6)$ was given 20 -min access to saccharin, followed immediately by an IP injection of physiological saline $(.9 \%)$. Following this treatment, all subjects were given 20-min access to water for 3 consecutive recovery days. On the day following the last recovery day, all subjects were given 20 -min access to saccharin in a one-bottle test of the aversion to saccharin. Immediately following this test, Groups $10,20,50$, and 80 were given an IP injection of $10,20,50$, and $80 \mathrm{mg} / \mathrm{kg}$ morphine sulfate, respectively. Group $\mathrm{C}$ received an injection of saline. Again, 3 recovery days were given after the conditioning trial.

This cycle of conditioning trial followed by three recovery days was repeated until all subjects had received five complete cycles. Following the fifth cycle, a final one-bottle test of the aversion to saccharin was given.

Phase 2. Following the final one-bottle test of Phase 1, subjects in Groups 20,50, and 80 were immediately given an IP injection of 20,50 , and $80 \mathrm{mg} / \mathrm{kg}$ morphine sulfate, respectively. As above, 3 recovery days followed this treatment. This cycle was repeated until six additional cycles had been completed. Following the last cycle (Cycle 11), a final one-bottle test of the aversion to saccharin was given.

\section{RESULTS}

All determinations of statistical significance were made at $\mathrm{p}<.05$.

\section{Phase 1}

Over the 12 water-adaptation days, rats in all groups gradually increased their consumption of water, drinking approximately $13 \mathrm{ml} /$ day over the final 3 days. There were no significant differences in water consumption among groups at this point. When saccharin replaced water on Day 13, there were no significant changes in consumption from the water baseline for any group of subjects. Group 20 drank significantly more saccharin on the first conditioning trial than Group $\mathrm{C}$ or $10, \mathrm{t}(12)=2.78$ and $t(14)=2.30$. There were no significant differences in saccharin consumption among any other remaining groups.

On the first one-bottle test of the aversion to saccharin (Conditioning Trial 2), there were no significant differences in saccharin consumption among groups, with no group drinking significantly different amounts of saccharin on this test from its initial saccharin baseline (see Figure 1). On the final aversion

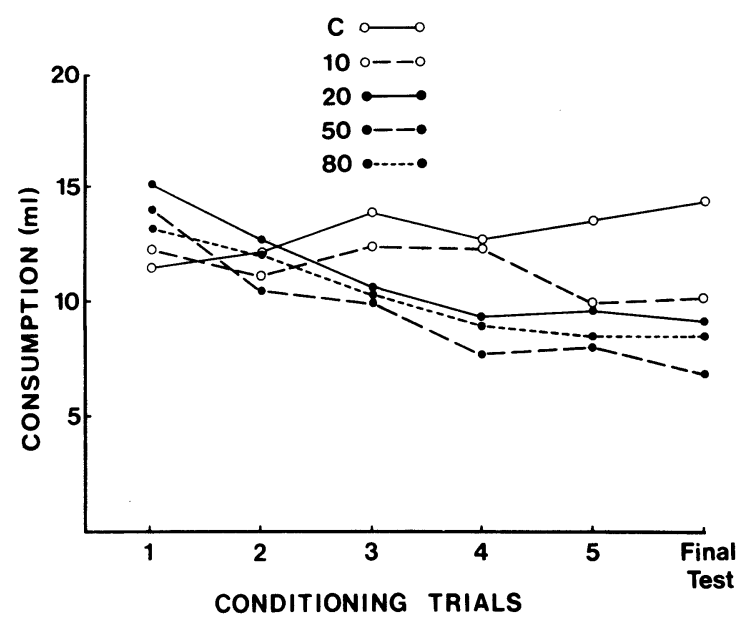

Figure 1. Mean consumption of saccharin for Groups C, 10, 20, 50, and 80 over repeated conditioning trials during Phase 1. 
test (following the fifth conditioning trial), however, Groups 20, 50, and 80 had significantly decreased consumption of saccharin below their initial saccharin baseline, $F(1,46)=17.33$. Groups $C$ and 10 did not significantly change their consumption of saccharin from their initial saccharin baselines. On the final aversion test, all groups injected with morphine drank significantly less saccharin than the saline-injected Group $C, F(1,34)=8.52$. There were no significant differences in consumption of saccharin among any of the groups injected with morphine (see Figure 1, final test).

There was considerable individual variability in the effect of morphine on consumption of saccharin in Groups 20, 50, and 80 (see Figure 2). Although there were no clear differences in the range of consumption or amount of variability among these three groups, these measures were quite large within each group. For example, the standard deviations of saccharin consumption on the final aversion test of Phase 1 for Groups 20, 50, and 80 were 5.79, 5.75 and 5.14, respectively. This variability is in contrast to the consistency within Groups $C$ and 10, which had standard deviations of .99 and 1.59 , respectively. While several subjects in Groups 20, 50, and 80 completely, or nearly completely $(0-2 \mathrm{ml})$, avoided saccharin consumption, others drank intermediate amounts $(5-9 \mathrm{ml})$ and still others drank as much as nonpoisoned controls $(14-16 \mathrm{ml})$. Although the mean consumption of saccharin was not significantly different among morphine-injected subjects, it is clear that there was much less variability in Group 10 than in groups that received larger doses of morphine.

\section{Phase 2}

Consumption of saccharin by Groups 20,50, and 80 did not change significantly from the final aversion test of Phase 1 to the final aversion test of Phase 2. On this latter aversion test, there were no significant differences in consumption of saccharin among Groups 20, 50, and 80. Each group drank approximately $8.5 \mathrm{ml}$ (see Figure 3). As in Phase 1, individual data within each group were still quite variable (see Figure 4). The standard deviations of saccharin consumption on the final aversion test of Phase 2 for Groups 20, 50, and 80 were 5.52, 6.73, and 5.32, respectively. Although there was considerable variability within each group, consumption of saccharin for any individual subject was quite consistent over repeated conditioning trials. The mean standard deviations of saccharin consumption over Conditioning Trials 6-11 for Groups 20, 50, and 80 were 1.65, 1.20 , and 1.48 , respectively. Comparison of the individual data for any particular subject demonstrates this individual consistency in consumption across repeated conditioning trials (see Figures 2 and 4).

\section{DISCUSSION}

Although no group showed an aversion to saccharin following a single saccharin-morphine pairing, repeated conditioning trials did result in a moderate aversion to the saccharin solution. However, the rats still drank some saccharin, even after repeated conditioning trials. While quite consistent with other reports on morphine-based aversions (Berger, 1972;

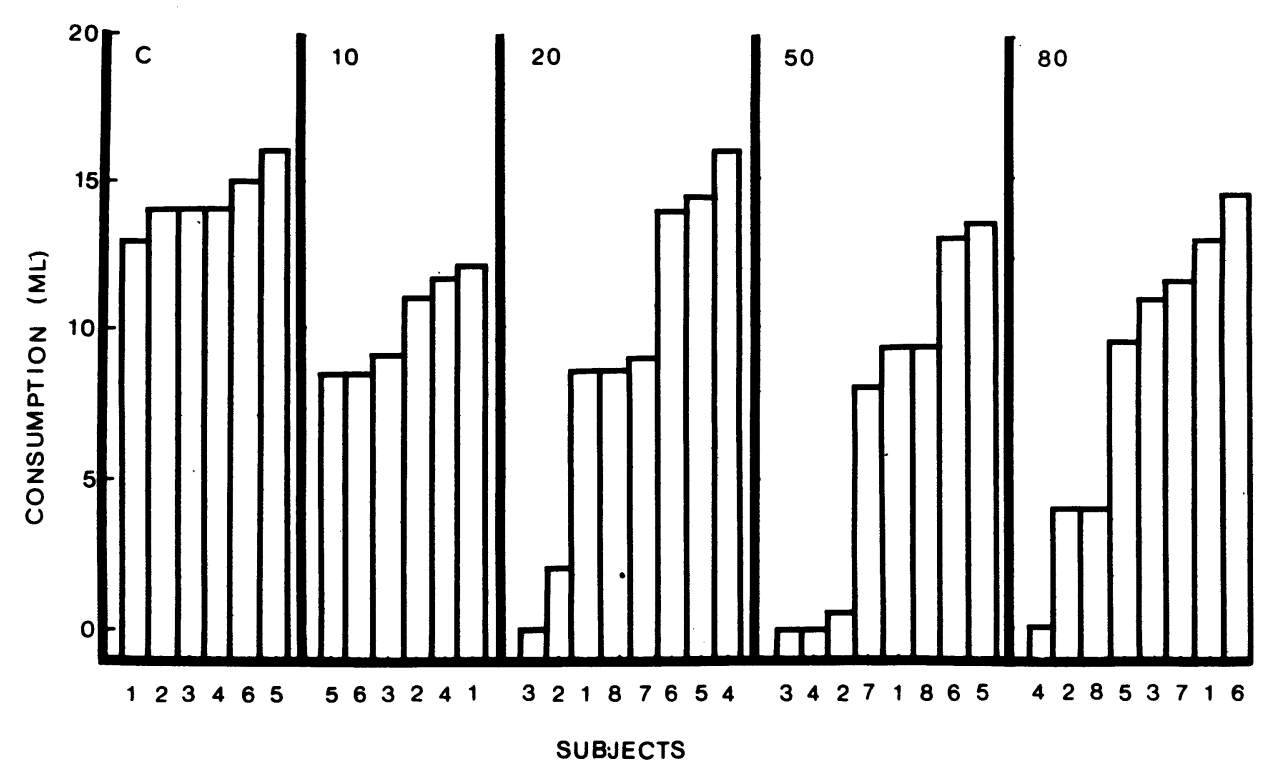

Figure 2. Consumption of saccharin for individual subjects in Groups $\mathrm{C}, 10,20,50$, and 80 on the final aversion test of Phase 1. 


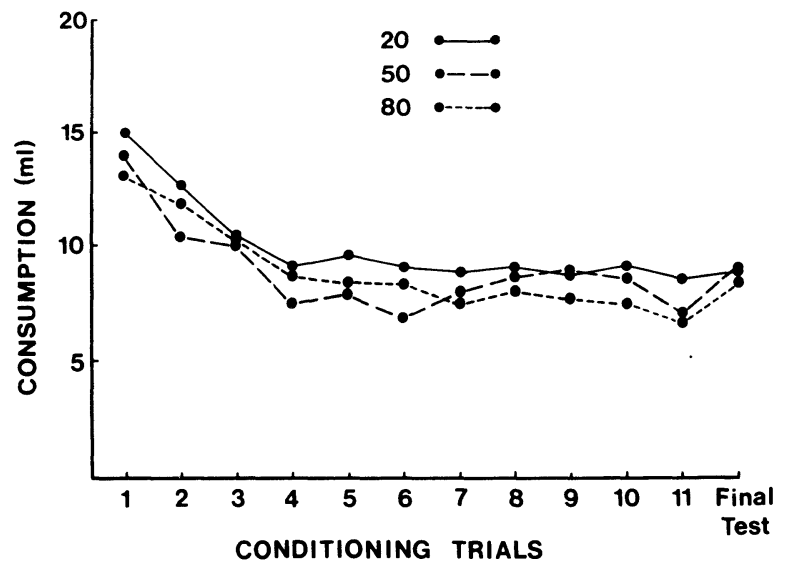

Figure 3. Mean consumption of saccharin for Groups 20, 50, and 80 over repeated conditioning trials in Phase 1 and Phase 2.

Coussens et al., 1973; Farber et al., 1976; Goudie et al., 1976; Jacquet, 1973; Parker et al., 1973), these data are in sharp contrast to the aversions typically induced by emetic USs. Lithium chloride, for example, produces strong aversions after only one trial (Nachman \& Ashe, 1973; Nachman \& Hartley, 1975) and complete aversions when repeated trials are given (Fenwick et al., 1975; Riley et al., 1976).

After five conditioning trials, all groups injected with morphine consumed less than control animals, drinking an average of approximately $8-10 \mathrm{ml}$. However, there was no differential effect on mean consumption attributable to the dose of morphine. Similar results using smaller doses of morphine have recently been reported (Farber et al., 1976; Jacquet, 1973; LeBlanc \& Cappell, 1975). Nachman and Ashe (1973) and Rolls and Rolls (1973), on the other hand, have demonstrated that as the amount or dose of $\mathrm{LiCl}$ is increased, the strength of the aversion increases. Thus, the absence of a graded effect of morphine dose also contrasts with the typical outcome of aversion studies which use emetics.

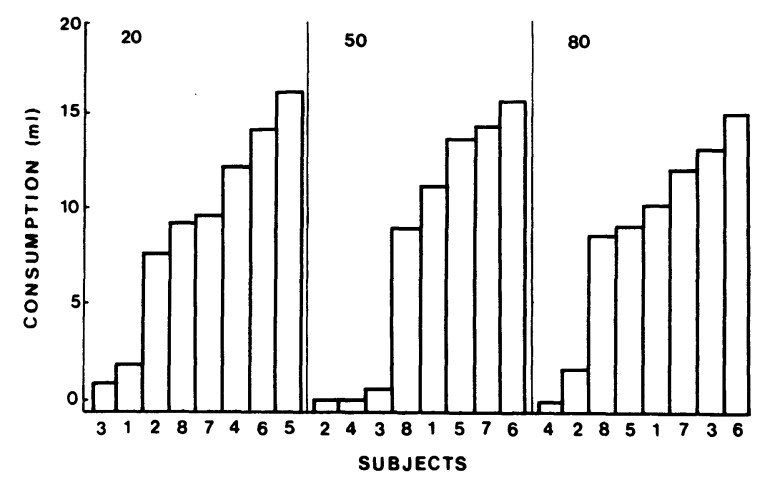

Figure 4. Consumption of saccharin for individual subjects in Groups 20, 50, and 80 on the final aversion test of Phase 2.
Although the average consumption for all morphineinjected subjects was approximately $8 \mathrm{ml}$, individual data within each group were quite variable; subjects consumed a range of $0-16 \mathrm{ml}$. This variability is in marked contrast to the consistently large aversions seen when repeated saccharin-lithium chloride pairings are given (Riley et al., 1976).

These data are compatible with the suggestion that drugs of abuse, e.g., morphine, amphetamine, and $\Delta^{9}$ THC, and emetic drugs, e.g., cytoxan, emetine, and $\mathrm{LiCl}$, act on very different physiological systems in establishing aversions (Amit et al., in press; Cappell \& LeBlanc, in press; Elkins, 1974; Sklar \& Amit, in press). These different loci of drug action may produce different types and/or strengths of conditioning, and thereby, different levels and amounts of variability in performance.

Although morphine-induced aversions were variable and moderate, it is possible that the physiological system underlying morphine and emetic-based aversions is the same. The activation of such a system, however, might be different for individual drugs. One particular system which might be generally involved in conditioned food aversions is the hypothalamic-pituitary-adrenal axis (Ader, 1976; Braveman, 1977; Hennessy, Smotherman, \& Levine, 1976; Kendler, Hennessy, Smotherman, \& Levine, 1976; Rigter \& Popping, 1976; Riley et al., 1976; Smotherman, Hennessy, \& Levine, 1976a, 1976b; Watson \& Riley, Note 1). A number of drugs which are used to establish food aversions also elicit adrenocortiocotrophic hormone (ACTH) (Riley et al., 1976). This correlation is supported by the fact that both pharmacological interventions and physiological manipulations that alter baseline levels of ACTH as well as the ACTH response to a stressor also alter conditioned food aversions (Riley \& Clarke, 1977). In relation to the present data, Watson and Riley (Note 1) have demonstrated that although both morphine $(50 \mathrm{mg} / \mathrm{kg})$ and $\mathrm{LiCl}(.15 \mathrm{M} \mathrm{LiCl}, 12 \mathrm{mg} / \mathrm{kg})$ elicit ACTH, the ACTH response to morphine is asymptotically weaker, shorter-lived, and more variable than that produced by $\mathrm{LiCl}$. This differential activation of the pituitary-adrenal system may provide some basis for the findings in the present report as well as providing some support for the notion of a general physiological mechanism underlying conditioned taste aversions (Braveman, 1977; Riley et al., 1976).

\section{REFERENCE NOTE}

1. Watson, B., \& Riley, A. Effects of lithium chloride and morphine sulfate on blood corticosterone levels in the rat. Paper presented at the meeting of the Canadian Psychological Association, Toronto, Ontario, June 1976. 


\section{REFERENCES}

ADER, R. Conditioned adrenocortical steroid elevations in the rat. Journal of Comparative and Physiological Psychology, 1976, 90, 1156-1163.

Amit, Z., Levitan, D. E., Brown, Z. W., \& Rogan, F. Possible involvement of central factors in the mediation of conditioned taste aversions. Neuropharmacology, in press.

BERGER, B. Conditioning of food aversions by injections of psychoactive drugs. Journal of Comparative and Physiological Psychology, 1972, 81, 21-26.

Braveman, $\mathbf{N}$. What studies on pre-exposure to pharmacological agents tell us about the nature of the aversion-inducing agent. In L. M. Barker, M. Best, \& M. Domjan (Eds.), Learning mechanisms in food selection. Waco, Texas: Baylor University Press, 1977.

Cappell, H., \& LeBlanc, A. Parametric investigations of the effects of prior exposure to amphetamine and morphine on conditioned gustatory aversion. Psychopharmacology, 1977, 51, 265-271.

CaPpell, H., \& LeBlanc, A. Gustatory avoidance conditioning by drugs of abuse: Relationships to general issues in research on drug dependence. In N. W. Milgram, L. Krames, \& T. M. Alloway (Eds.), Food aversion learning. New York: Plenum Press, in press.

Cappell, H., LeBlanc, A., \& Endrenyi, L. Aversion conditioning by psychoactive drugs: Effects of morphine, alcohol, and chlordiazepoxide. Psychopharmacologia, 1973, 29, 239-246.

Cappell, H., LeBlanc, A., \& Herling, S. Modification of punishing effects of psychoactive drugs in rats by previous drug experience. Journal of Comparative and Physiological Psychology, 1975, 89, 347-356.

Coussens, W. Conditioned taste aversion: Route of drug administration. In J. M. Singh \& H. Lal (Eds.), Drug addiction: Neurobiology and influences on behavior (Vol. 3). Miami: Symposium Specialists, 1974.

Coussens, W., Crowder, W., \& Davis, W. Morphine induced saccharin aversion in a-methyltyrosine pretreated rats. Psychopharmacologia, 1973, 29, 151-157.

ElKINS, R. Individual differences in bait shyness: Effects of drug dose and measurement technique. Psychological Record, 1973, 23, 349-358.

Elkins, R. Conditioned flavor aversions to familiar tap water in rats: An adjustment with implications for aversion therapy treatment of alcoholism and obesity. Journal of Abnormal Psychology, 1974, 83, 411-417.

Farber, P., Gorman, J., \& ReID, L. Morphine injections in the taste aversion paradigm. Physiological Psychology, 1976, 4, 365-368.

Fenwick, S., Mikulka, P., \&.Klein, S. The effect of different levels of pre-exposure to sucrose on the acquisition and extinction of a conditioned aversion. Behavioral Biology, 1975, 14, 231-235.

GAMZU, E. The multifaceted nature of taste-aversion inducing agents: Is there a single common factor? In L. M. Barker, M. R. Best, \& M. Domjan (Eds.), Learning mechanisms in food selection. Waco, Texas: Baylor University Press, 1977.

Garcia, J., \& Koelling, R: Relation of cue to consequence in avoidance learning. Psychonomic Science, 1966, 4, 123-124.

Garcia, J., Kimeldorf, D., \& Koelling, R. Conditioned aversion to saccharin resulting from exposure to gamma. radiation. Science, 1955, 122, 157-158.

Goudie, A., \& Thornton, E. Effects of drug experience on drug induced conditioned taste aversions: Studies with amphetamine and fenfluramine. Psychopharmacologia, 1975, 44, 77-82.

Goudie, A., Thornton, E., \& WheEler, T. Drug pretreatment effects in drug induced taste aversion: Effects of dose and duration of pretreatment. Pharmacology, Biochemistry, and Behavior, 1976, 4, 629-633.

Hennessy, J., Smotherman, W., \& Levine, S. Conditioned taste aversion and the pituitary-adrenal system. Behavioral Biology, 1976, 16, 413-424.

IONESCU, E., \& Burešova, O. Failure to elicit conditioned taste aversion by severe poisoning. Pharmacology, Biochemistry, and Behavior, 1977, 6, 251-254.

JACQUET, Y. F. Conditioned aversion during morphine maintenance in mice and rats. Physiology and Behavior, 1973, $11,527-541$

Kendler, K., Hennessy, J. W., Smotherman, W. P., \& LEVINE, S. An ACTH effect on recovery from conditioned taste aversion. Behavioral Biology, 1976, 17, 225-229.

LeBlanc, A., \& Cappell, H. Attenuation of punishing effects of morphine and amphetamine by chronic prior treatment. Journal of Comparative and Physiological Psychology, 1974, 87, 691-698.

LeBlanc, A., \& Cappell, H. Antagonism of morphine-induced aversive conditioning by naloxone. Pharmacology, Biochemistry, and Behavior, 1975, 3, 185-188.

Martin, G., \& Storlien, L. Anorexia and conditioned taste aversions in the rat. Learning and Motivation, 1976, 7, 274-282.

NaChMAN, M., \& Ashe, J. Learned taste aversions in rats as a function of dosage, concentration, and route of administration of LiCl. Physiology and Behavior, 1973, 10, 73-78.

NACHMAN, M., \& HaRTLEY, P. Role of illness in producing learned taste aversions in rats: A comparison of several rodenticides. Journal of Comparative and Physiological Psychology, 1975, 89, 1010-1018.

Parker, L., Failor, A., \& Weidman, K. Conditioned preferences in the rat with an unnatural need state: Morphine withdrawal. Journal of Comparative and Physiological Psychology, 1973, 82, 294-300.

Rigter, H., \& Popping, A. Hormonal influences on the extinction of conditioned taste aversion. Psychopharmacologia, 1976, 46, 255-261.

RILEY, A., \& Clarke, C. Conditioned taste aversions: A bibliography. In L. M. Barker, M. Best, \& M. Domjan (Eds.), Learning mechanisms in food selection. Waco, Texas: Baylor University Press, 1977.

Riley, A., JAcobs, W. J., \& LoLoRdo, V. M. Drug exposure and the acquisition and retention of a conditioned taste aversion. Journal of Comparative and Physiological Psychology, 1976, 90, 799-807.

Rolls, B., \& Rolls, E. Effects of lesions in the basolateral amygdala on fluid intake in the rat. Journal of Comparative and Physiological Psychology, 1973, 83, 240-247.

SKLAR, L., \& AMIT, Z. Manipulations of catecholamine systems block the conditioned taste aversion induced by selfadministration drugs. Neuropharmacology, in press.

Smotherman, W., Hennessy, J., \& Levine, S. Plasma corticosterone levels during recovery from $\mathrm{LiCl}$ produced taste aversions. Behavioral Biology, 1976, 16, 401-412. (a)

Smotherman, W., Hennessy, J., \& Levine, S. Plasma corticosterone levels as an index of the strength of illness induced taste aversions. Physiology and Behavior, 1976, 17, 903-908. (b)

White, N., Sklar, L., \& AMIT, Z. The reinforcing action of morphine and its paradoxical side effect. Psychopharmacology, 1977, 52, 63-66.

WISE, R., YoKeL, R., \& DEWITT, H. Both positive reinforcement and conditioned aversion from amphetamine and from apomorphine in rats. Science, 1976, 191, 1273-1275.

(Received for publication August 29, 1977; accepted October 26, 1977.) 